\title{
On 6G Visions and Requirements
}

\author{
Jyrki T. J. Penttinen
}

Senior Technology Manager at GSMA, Atlanta, Georgia, United States

E-mail: jyrki.penttinen@outlook.com

Received 15 April 2021; Accepted 07 November 2021;

Publication 16 December 2021

\begin{abstract}
$6 \mathrm{G}$ represents standardized communication systems that will be commercially available in 2030s. Even if the initial 5G networks, basing on the 3GPP Release 15 , have hardly started become commercially available gradually as of 2019 and their large-scale deployment is still years away, industry is already keen to envision the justification and performance of the forthcoming generation. While there are no concrete $6 \mathrm{G}$ standards produced at this stage, their planning will benefit from realistic indications of the requirements and type of usage. The task is not straightforward as users, including a variety of verticals with their rather different communication environments, are sometimes not capable of expressing their future needs in technical terms nor industry might be able to prognosticate the demand that has not yet equivalence in preceding systems. This paper analyses some of the most important current visions of key standardization bodies and assesses indications of the industry for the potential requirements, service types, use cases, and architectural and functional models that can serve as a building block for the actual realization of the visions. This paper also presents means that can be applied in further interpretation and assessment of the vertical
\end{abstract}

Journal of ICT Standardization, Vol. 9_3, 311-326.

doi: 10.13052/jicts2245-800X.931

(C) 2021 River Publishers 
needs and priorities, with examples reflecting the benefits of Network Slice requirements that the GSMA North Americas Network Slicing Taskforce studied for foreseen near future environment and that may be extended to be utilized also in exploration of $6 \mathrm{G}$ requirements.

Keywords: Vertical needs, IMT-2030 standardization, 6G performance, 6G requirements.

\section{Introduction}

Since the very first mobile communication generation - which refers to the now obsolete analogue mobile systems of 1980s with mainly wireless voice call service capability - each of the posterior decade has witnessed the arise of a new generation. $2 \mathrm{G}, 3 \mathrm{G}, 4 \mathrm{G}$, and now $5 \mathrm{G}$ are all evolving in a parallel fashion as for the standardization is considered. Each generation has their evolving use base. In practice, the regional scenarios of the deployment and utilization of different generations can be considered to be either parallel or overlapping, depending on the varying market segments. Figure 1 presents the foreseen global development of the relative utilization of $2 \mathrm{G}-5 \mathrm{G}$. [1] As can be seen, the importance of least spectral-efficient $2 \mathrm{G}$, predominantly represented by Global System for Mobile Communications (GSM), will decrease although it serves still especially IoT devices and developing markets for

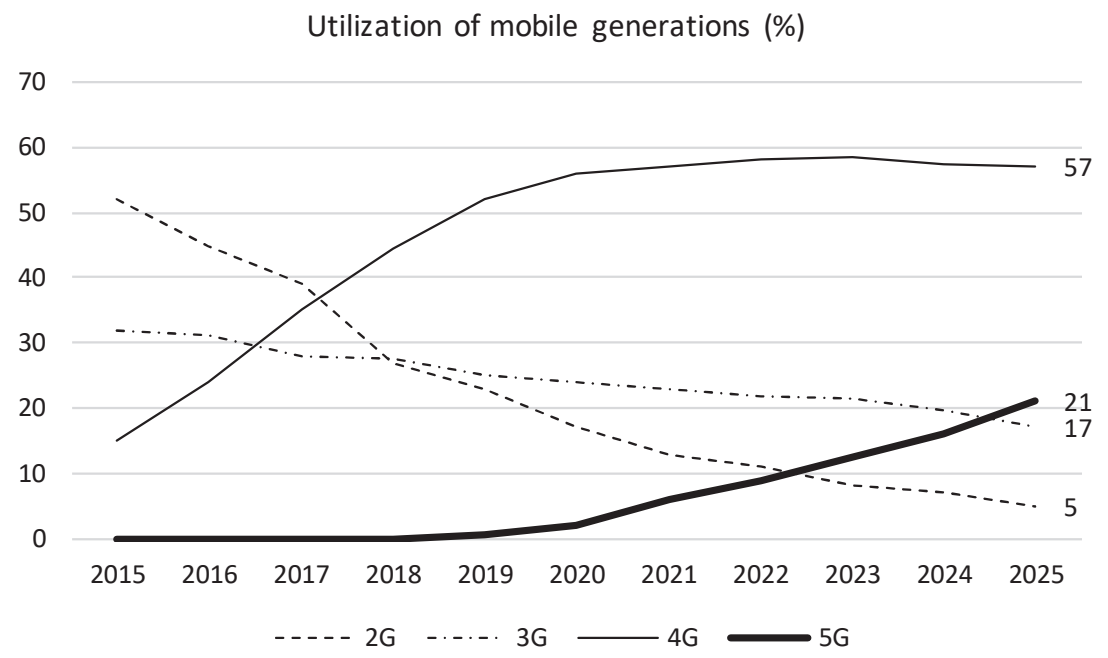

Figure 1 Relative utilization of mobile communication generations [1]. 
years to come. As for $5 \mathrm{G}$, its deployment will take place gradually, and by 2025 , it will serve an estimated $21 \%$ share of the global use base while in developed markets such as in the USA, Europe and Asia the regional utilization may be close to $50 \%$. Still in $2025,4 \mathrm{G}$ is clearly the most dominant generation.

Meanwhile, $6 \mathrm{G}$ is still under early visioning. Of the most active entities considering the foreseen requirements and form of the next generation, the most relevant is the International Telecommunication Union (ITU), which is preparing high-level performance statements for $6 \mathrm{G}$ systems in a form of the IMS (International Mobile Telecommunications).

The ITU has performed this task since the production of IMT-2000 of $3 \mathrm{G}$, proceeded by the IMT-Advanced for $4 \mathrm{G}$, and IMT-2020 for $5 \mathrm{G}$. As has been the case previously, also the global requirements for $6 \mathrm{G}$, referred most probably to as IMT-2030, will be an iterative joint effort with the industry and standardization bodies such as the Standard Setting Organizations (SDOs) of the Third Generation Partnership Project (3GPP).

As an example of the globally recognized 5G, the ITU approved three new technologies that conform with the IMT-2020 vision and strict performance requirements: 5G-SRIT and 3GPP 5G-RIT of the $3 \mathrm{GPP}$ and $5 \mathrm{Gi}$ of the Telecommunications Standards Development Society India (TSDSI). The IMT vision requires that the candidate technologies are sufficiently detailed to enable worldwide compatibility of operation and equipment, including roaming. As a result of the ITU evaluation process, the first release of IMT2020 supporting $5 \mathrm{G}$ is now a set of terrestrial radio interface specifications incorporated into a global standard of the ITU-R Recommendation "Detailed specifications of the radio interfaces of IMT-2020." This same process will be applied to $6 \mathrm{G}$, too, and the $3 \mathrm{GPP}$ among other contributors will take it into account in their Technical Specification (TS) development in suitable Releases well before 2030, supported by preceding 6G-related Technical Reports (TR) [2].

\section{Entities Forming the Base for $6 \mathrm{G}$}

Although the IMT will be elemental for $6 \mathrm{G}$, the work of the ITU is still in the initial phase and relates merely to discussions of visions. As an example, the TS "Architecture Framework" of the Study Group SG13 produced such outlook in 2020. Meanwhile, industry is advancing with ideas to concretize the visions and early candidate technologies. This is an iterative process, which helps ITU form the concrete IMT requirements for $6 \mathrm{G}$. 
Table 1 Example of entities considering and contributing to $6 \mathrm{G}$ development

\begin{tabular}{ll}
\hline Entity & \multicolumn{1}{c}{ Role, Source } \\
\hline ITU-T SG13 & The Future Networks Study Group of ITU-T considers \\
candidate ideas for IMT-2030 requirements [3]. & Definition of requirements for 6G radio technologies. \\
ITU-R & ITU-R Working Party 5D has invited organizations to \\
& provide inputs for its June and October meetings in 2021 to \\
& develop "Future Technology Trends towards 2030 and \\
& beyond" report [4]. \\
& The future Word Radiocommunication Conferences will \\
& discuss radio band extensions that aim to serve 6G in 2030 \\
& and beyond. \\
ITU-R WRC & The role of 3GPP, as an entity representing various globally \\
& significant SDOs, will be essential in a form of concrete \\
candidate proposal of the forthcoming ITU IMT for 6G. & European Union, through the EC, has established various \\
3GPP & research programs for 5G and is preparing the same for 6G. \\
Examples of the latter are Hexa-X and SNS-PPP [5]. \\
ATIS-lead initiative in North America region to discuss and \\
promote solutions for 6G era with industry representatives. \\
The US government, through agencies such as Federal \\
and Communication, Japan
\end{tabular}

Table 1 summarizes some of the entities contributing to this process, based on the publicly available information.

\section{Current 6G Visions}

The $6 \mathrm{G}$ era is still rather far away from the commercial deployment, which can be estimated to begin gradually approx. 2030. In fact, there are no commonly agreed visions yet available regardless of many forums discussing the ideas. Of the various sources of information, some statements commonly indicate that $6 \mathrm{G}$ will be connecting physical and digital words, and serves as a platform to make digital twin a reality. Digital twin in this context refers to the ability of the system to represent the real-world objects in a 
digital form in a near-real time. What can be interpreted from the statements of various sources, such as ITU NET-2030 [3] and Next G Alliance [6] is, that $6 \mathrm{G}$ requirements are driven predominately on use case basis that widen the previously applied principle of presenting performance characteristics in terms of technical attributes and their values.

As stated in [7], 6G will integrate physical, biological, and digital worlds along with the evolved radio frequency communication, to facilitate the inclusion of variety of components such as robots, digital twins, artificial intelligence, emotion-driven devices, and brain-machine interface. This setup is capable of enabling a complete cyber-physical-biological communication experience.

The ITU-T SG13 is one of the most concrete sources of information as it paves the way for the forthcoming ITU IMT requirements for $6 \mathrm{G}$. It considers the development of the 5G capabilities and presents opportunity areas for the further development and some probable use cases such as holographic communication that indicates the respective requirements beyond the capabilities of 5G. The contents of, e.g., Architecture Framework Specification produced by the SG13 in June 2020, the following indications can be presented: 6G needs to tackle 10-100 times higher data speeds, considerably higher system capacity, spectrum efficiency, and terminal velocities, better radio service coverage, and lower latency. Furthermore, $6 \mathrm{G}$ is expected to better interconnect things.

Table 2 presents some of the publicly available, concrete $6 \mathrm{G}$ vision statements of industry and standardization, and comparative statements of the ITU-T SG13 Network 2030 visions.

The indications of the $6 \mathrm{G}$ visions in Table 2 represent needs that may not be feasible to comply with even further evolved $5 \mathrm{G}$. These indications, among other entities forming such statements via academic research and practical investigation, will be useful information sources for forming the ITU IMT2030 requirements for the forthcoming $6 \mathrm{G}$ systems.

Table 2 presents a snapshot of the high-level visions whereas the various current and future initiatives will produce concrete proof of concepts. This is a long-term effort and the process will be rather similar to the applied research of the various items that were candidate options for the $5 \mathrm{G}$ requirements and standardization. This effort is thus an iterative process so that the ITU will evaluate the realistic expectations produced by the numerous concepts for technical performance of the future radio and core functions, architecture models, and other relevant aspects forming the IMT-2030 requirements. 
Table 2 Assessment of selected 6G vision statements

\begin{tabular}{|c|c|c|}
\hline Vision Statement & Relevancy assessment & Ref. \\
\hline $\begin{array}{l}\text { ITU NET-2030 } \\
\text { requirements } \\
\text { include: simplicity; } \\
\text { native } \\
\text { programmability and } \\
\text { soft re-architecting; } \\
\text { backward } \\
\text { compatibility; } \\
\text { heterogeneous } \\
\text { communication, } \\
\text { compute, storage, } \\
\text { service and their } \\
\text { integration; native } \\
\text { slicing; unambiguous } \\
\text { naming network } \\
\text { functions and } \\
\text { services; Intrinsic } \\
\text { anonymity and } \\
\text { security support for } \\
\text { all network } \\
\text { operations; } \\
\text { resilience; network } \\
\text { determinism. }\end{array}$ & $\begin{array}{l}\text { - Along with virtualized network, adding } \\
\text { service may increase complexity and } \\
\text { result failures - the solutions must be kept } \\
\text { simple; } \\
\text { - architecture must be highly flexible; } \\
\text { - Network } 2030 \text { must support service and } \\
\text { network device decoupling; } \\
\text { - heterogeneity must be multi-dimensional; } \\
\text { - native slices should enable efficient use of } \\
\text { many types of Network } 2030 \text { services; } \\
\text { - user and systems will not access a specific } \\
\text { server but rather the hosted content, } \\
\text { function or service; } \\
\text { - Network } 2030 \text { will be a critical national } \\
\text { infrastructure for security and economy; } \\
\text { - To avoid future cyber-attacks, the } \\
\text { Network } 2030 \text { must have adequate means } \\
\text { to mitigate the respective impact through } \\
\text { appropriate controls on all the planes of } \\
\text { the telecommunication network that are } \\
\text { under risk. } \\
\text { - Network } 2030 \text { must be adaptive to } \\
\text { accommodate both deterministic and } \\
\text { non-deterministic service requirements. }\end{array}$ & FG-NET-2030 [8] \\
\hline $\begin{array}{l}6 \mathrm{G} \text { needs to solve } \\
\text { limitations of } 5 \mathrm{G} \text {, } \\
\text { e.g., system coverage } \\
\text { and IoE; } 6 \mathrm{G} \text { must } \\
\text { serve Ubiquitous } \\
\text { Intelligent Mobile } \\
\text { Society. }\end{array}$ & $\begin{array}{l}\text { This statement indicates the high } \\
\text { expectations of the ecosystem for the } 6 \mathrm{G} \\
\text { technologies, and the need for future } \\
\text { technologies to serve as a platform in } \\
\text { evolving society. }\end{array}$ & Shanzhi Chen [9] \\
\hline $\begin{array}{l}\text { Holographic media } \\
\text { and multi-sense } \\
\text { including haptic } \\
\text { communication } \\
\text { services will be } \\
\text { examples of the } \\
\text { typical } \\
\text { representatives of } 6 \mathrm{G} \\
\text { according to ITU-T. }\end{array}$ & $\begin{array}{l}\text { Current } 5 \mathrm{G} \text { use cases often mention } \\
\text { multimedia through Augmented Reality and } \\
\text { Virtual Reality (AR/VR), but } 5 \mathrm{G} \\
\text { performance will be limited for } \\
\text { near-real-time holographic communications. } \\
6 \mathrm{G} \text { can be expected to provide engaging and } \\
\text { realistic user experiences via true rendering } \\
\text { of an object. Holographic applications } \\
\text { include many realms such as entertainment, } \\
\text { teleconferencing, tele-surgery, and remote } \\
\text { holographic presence. }\end{array}$ & ITU-T [10] \\
\hline
\end{tabular}


Table 2 Continued

\begin{tabular}{lll}
\hline Vision Statement & \multicolumn{1}{c}{ Relevancy assessment } & \multicolumn{1}{c}{ Ref. } \\
\hline The Hexa-X vision is to connect & European Union - founded & Hexa-X [5] \\
human, physical, and digital & Hexa-X has connectivity \\
worlds with a fabric of 6G key & industry stakeholders and \\
enablers. & research entities considering \\
& development towards 6G. The \\
& Hexa-X project includes \\
& developing key technology \\
& enablers of new radio access \\
& technologies at high frequencies \\
& and high-resolution localization \\
& and sensing; connected \\
& intelligence through AI-driven \\
& air interface and governance for \\
& future networks, and 6G \\
& architectural enablers for \\
& network disaggregation and \\
& dynamic dependability. This \\
& activity considers the overall \\
& visions in practice. \\
& Next G Alliance can be assumed \\
to have important role in regional & Next G Alliance [6] \\
6G preparedness. It focuses on \\
technology commercialization \\
promoting a marketplace for 6G. & manufacturing, standardization \\
encompassing the lifecycle of \\
advance North American
\end{tabular}

\section{Possible Enablers for 6G}

According to [4], 6G will be a set of technologies forming the complete architecture. Thus, it can be expected that $6 \mathrm{G}$ is a combination of terrestrial, aerial (aircraft-mounted base stations) and space (satellite) systems. Reflecting the current development, it can be estimated that some of the technologies such as network functions virtualization (NFV) and software defined networking (SDN) keep evolving and serve in $6 \mathrm{G}$ era, too. This means that the related services such as Network Slicing (NS) will play important role in 6G. 
Table 3 Some of the potential, further evolving enablers in $6 \mathrm{G}$

\begin{tabular}{ll}
\hline Enabler & \multicolumn{1}{c}{ Estimated Role in 6G } \\
\hline Network Slicing & Along with the Network Functions Virtualization, Network Slicing \\
will be more granular and serves the varying needs of multitude of \\
verticals optimizing the network resources.
\end{tabular} Fommon APIs $\quad \begin{aligned} & \text { Further evolved Common APIs for Northbound Interfaces of the } \\
& \text { 3GPP SA6 has potential to extend the developers' opportunities to } \\
& \text { better access and utilize the network resources. 6G will benefit from } \\
& \text { the concept. } \\
& \text { Service Enabler Architecture Layer for Verticals as defined by the } \\
& \text { 3GPP SA6 supports vertical applications in V2X and other } \\
& \text { domains. The application and signalling plane entities for } \\
& \text { application-enabling services can relate to, e.g., group, } \\
& \text { configuration, location, identity and key, as well as network } \\
& \text { resource management in a reusable way across vertical applications. } \\
& \text { SEAL can turn out to be relevant enabler in 6G. } \\
& \text { Application layer support for V2X services enables use and } \\
& \text { deployment of V2X services over 3GPP systems. The V2X } \\
& \text { Application Enabler layer resides on top of the SEAL architecture. } \\
& \text { The V2XAPP provides capabilities in 4G such as V2X message } \\
& \text { distribution, service continuity, application resource management, } \\
& \text { and dynamic group management via the 4G system capabilities, and } \\
& \text { can pave the way for similar tasks in 6G. } \\
& \text { OFDM has served as a feasible base technology for LTE downlink } \\
& \text { and 5G NR by adjusting its parameters to cope with the } \\
& \text { technological performance goals. OFDM in its further evolved form } \\
& \text { can serve as a feasible candidate technology also for 6G although } \\
& \text { many other variants can emerge, too. } \\
& \text { Open Radio Access Network is currently evolving concept for the } \\
& \text { abstraction of the RAN modules, that provides the execution of } \\
& \text { functions also on cloud. It is relevant candidate enabler also in 6G. }\end{aligned}$

Table 3 summarizes some of the current enablers planned or utilized in $4 \mathrm{G}$ and $5 \mathrm{G}$, and that can be strong candidate items evolving further in $6 \mathrm{G}$ era, too.

\section{Network Slice Assessment of Vertical Requirements}

\subsection{Network Slicing as a 6G Enabler}

One of the most logical current and future solutions to optimize verticalspecific performance of the networks resources is Network Slicing (NS). 
The development of $5 \mathrm{G}$ has already indicated the importance to understand end-user requirements along with the new service models that NS facilitates. NS provides ecosystem means for extending business models, and serves as technical base for advanced optimization for the operators in terms of available network resources and how to dedicate them to users, which in general are verticals with a diversity of needs. Along with the technical evolution, NS also provides new business opportunities. Thus, a Network Slicing Provider (NSP) can typically be a telecommunication service provider, which is the owner or tenant of the network infrastructures from which NSs are created. NSP can thus be a separate entity from the network infrastructure owner, that is, Mobile Network Operator (MNO). The NSP takes the responsibilities of managing and orchestrating corresponding resources that the Network Slicing consists of.

The network slice operators who are capable of understanding adequately the vertical needs are in a strong position to offer the optimal resources - not deviating from the desired performance to increase customer happiness, and at the same time, not exceeding unnecessarily the performance if it is not utilized in any case, in order to dedicate limited resources among the other users balancing with the respective the requirements.

The collection of the vertical needs for network slicing setup has been exercised already by different entities such as GSMA and ATIS. An example of the effort is the attribute and value assessment of the GSMA North Americas Network Slicing Taskforce related to regional key verticals. These activities found out that in order to adequately adjust a set of NSs, it is business-critical for NSP to understand the realistic needs. With such a variety and diversity of the requirements of verticals, network resource utilization must be optimized taking into account wide view of the complete ecosystem. This is a new aspect in the already highly complex optimization tasks of the operators, and automatized methods such as self-organizing network optimization techniques based on Artificial Intelligence (AI) and Machine Learning (ML) models may turn out to be essential to facilitate this task.

In the practical deployment of services and their enablers, such as regionally optimized set of NSs, the GSMA PRD NG.116 presents some of the most logical common slices to ensure fluent user experiences in the interoperable environment, including roaming scenarios that benefit from the uniform user experience offering cross the operator community. It can be assumed that this model for preparedness will continue being utilized also in the future for better coping with the requirements of $6 \mathrm{G}$ users. 


\subsection{Vertical Requirements Interpretation}

The GSMA NETSLIC Taskforce researched regional vertical needs of selected use cases in the North America market area during 2019-21. In this effort, the Taskforce designed and applied NS assessment process as depicted in Figure 2 [11]. Based on the designed process, the Taskforce applied the following steps:

(a) Regional Priority Verticals: Identify relevant verticals that can benefit from network slicing. Assess the priority of the verticals in terms of relevance of the markets the verticals represent. As an outcome, form a priority list of the verticals.

(b) Vertical Needs Assessment: Reach out to the priority verticals in order to understand the practical environment and needs for the communications technologies via their use cases, applying systematic information gathering process.

(c) Use Case Assessment: On the selected use cases, by understanding typical needs and challenges, form each use case into a list of relevant attributes and their value ranges.

(d) Network Slice Template Forming: Finally, map the attributes and their values into network slicing templates. Of the templates, GST (Generic Network Slice Template) lists the relevant attributes related to the use case whereas the NEST (Network Slice Type) presents the values for that GST.

The GST and NEST are essential information elements for the stakeholders that set up and manage network slices technically and commercially. The MNOs wanting to ensure fluent user experience and service level, considering

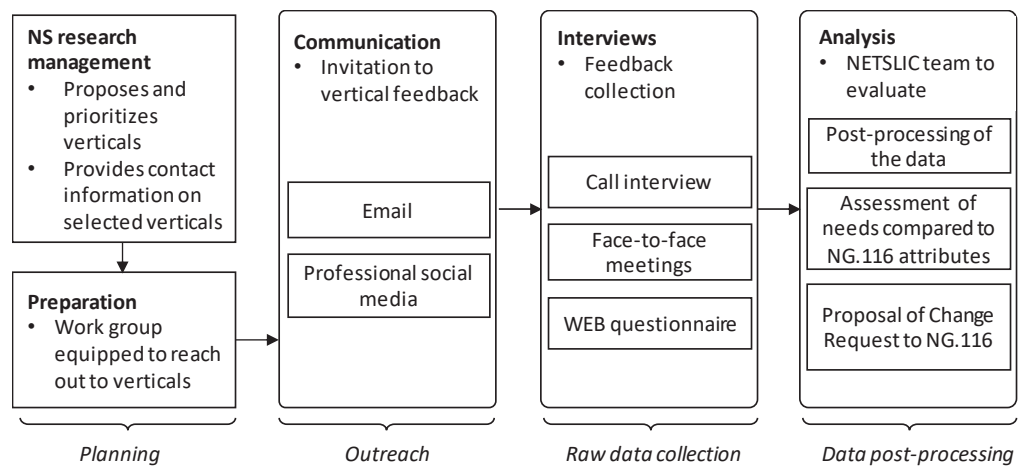

Figure 2 The process for vertical engagement and requirements assessment [11]. 
the home operator's network and well as the roaming scenarios, can use similar settings within the considered area.

\subsection{Use Case Example: Commercial Flight Telematics}

Commercial Flight Telematics is an example of vertical that the GSMA NETSLIC Taskforce has studied. The process depicted in Figure 2 was applied in commercial use case study of the transmission of telematics data $\log$ transfer that is triggered upon the landing of the plane at the airport. The communications link may be any available one such as Wi-Fi hotspot within the landing area, or cellular communications system of any of the commercially available generations. This use case relies on in-built IoT device of the aircraft that establishes connection autonomously with a ground server upon the landing of the aircraft.

In order to optimize the rather short period the plane stays on the ground, the aircraft starts sending the stored telematics data to the server for further processing immediately after establishing the connection. The IoT device can also receive SW updates and data contents, such as entertainment system's audio and video, as well as flight plan-related information. Being isolated system for the data transmission in uplink and downlink, there is no personto-person communication channel involved. In this specific use case, it can be assumed that the current solutions are largely based on $4 \mathrm{G}$ connectivity although also legacy technologies may be involved, as well as Wi-Fi and satellite communications.

The further assessment of this use case indicated that security is of utmost importance, and that in avionics domain, all the solutions need to be certified, which requires rather long time. Furthermore, along with the potential sunsetting of legacy cellular systems in certain areas, there is a need to consider future-proofed technologies with the focus of at least 15 years in the future. Finally, there are potential issues related to the interferences, outage areas and congestion of the Wi-Fi or cellular networks.

In this specific example, it can be noted that the requirements of the use case map largely with the capabilities of $4 \mathrm{G}$ and $5 \mathrm{G}$. Nevertheless, the telematics environment will develop during the next 10 years, so it can be expected that these requirements may largely benefit from $6 \mathrm{G}$ performance along with a) overall development of the enabling technologies; b) their adaptation to the commercial flight environment also during the flights.

As a result of this thought process, it may well turn out to be that upon the global and regional regulation - in addition to mere telematics 
Table 4 Commercial Flight Telematics Use Case requirements presented in a form of GSMA NG.116 GST and NEST, complemented by 6G evolution considerations

\begin{tabular}{|c|c|}
\hline GST & NEST \\
\hline 3.4.1. Availability & $\begin{array}{l}\text { Time for service delivers, divided by amount of time system is } \\
\text { expected to deliver service: High }(95-99.95 \%) \text {. The maximum value } \\
\text { defined now in } 5 \mathrm{G} \text { ( } 99.999 \text { in Release } 15 \text {, and } 99.9999 \text { in Release 16) } \\
\text { can further increase in } 6 \mathrm{G} \text { benefiting this use case. It is worth noting } \\
\text { the enhanced technical value range as such may not be the significant } \\
\text { aspect, but the capability of } 6 \mathrm{G} \text { to optimize the performance further } \\
\text { based on the characteristics and needs of use cases, by differentiating } \\
\text { the allocated performance figures is an important difference with the } \\
\text { current methods to manage } 4 \mathrm{G} \text { and } 5 \mathrm{G} \text { performance characteristics. }\end{array}$ \\
\hline $\begin{array}{l}\text { 3.4.2. Area of } \\
\text { service }\end{array}$ & $\begin{array}{l}\text { List of countries and areas the airline is operating in. The list is } \\
\text { specific to network slice providers and roaming agreements. }\end{array}$ \\
\hline $\begin{array}{l}\text { 3.4.5 Downlink } \\
\text { throughput per } \\
\text { network slice }\end{array}$ & $\begin{array}{l}\text { Guaranteed and maximum - Preferred guaranteed: } 1 \mathrm{~Gb} / \mathrm{s} \text { (total of the } \\
\text { network slice at the airport). While } 5 \mathrm{G} \text { is designed to provide } \\
\text { maximum of } 20 \mathrm{~Gb} / \mathrm{s} \text { for single user in downlink, } 6 \mathrm{G} \text { will be designed } \\
\text { to exceed this value possibly } 10 \text {-fold. }\end{array}$ \\
\hline 3.4.9 Isolation level & $\begin{array}{l}\text { Physical isolation of the resources of the network slices (highest } \\
\text { level). Data may be protected separately at the application level, in } \\
\text { which case the highest network slice isolation is not needed. }\end{array}$ \\
\hline $\begin{array}{l}\text { 3.4.24 Session and } \\
\text { service continuity }\end{array}$ & $\begin{array}{l}\text { Session and Service Continuity (SSC) mode }(1,2,3)-\text { SSC } 3 \text { for } \\
\text { highest assurance (changes to the user plane can be visible to the UE, } \\
\text { while the network ensures that the UE suffers no loss of connectivity). } \\
6 \mathrm{G} \text { may have wider set of SSC modes. }\end{array}$ \\
\hline $\begin{array}{l}\text { 3.4.28 Supported } \\
\text { device velocity }\end{array}$ & $\begin{array}{l}\text { Vehicular, i.e., } 120 \mathrm{~km} / \mathrm{h} \text { (data transmission starts automatically upon } \\
\text { planes taxing and continues when they are parked at the gate). } 5 \mathrm{G} \\
\text { allows maximum of } 500 \mathrm{~km} / \mathrm{h} \text { terminal speed. } 6 \mathrm{G} \text { may be able to } \\
\text { tolerate faster terminal speeds in an optimized and dynamic way } \\
\text { based on the respective use case requirements. As the attributes } \\
\text { contributing to the } 6 \mathrm{G} \text { performance are not yet available in } \\
\text { specification, the practical management of this attribute in the future } \\
6 \mathrm{G} \text { networks is an example of the opportunity to evolve technologies } \\
\text { beyond } 4 \mathrm{G} \text { and } 5 \mathrm{G} \text { based on foreseen use cases. }\end{array}$ \\
\hline $\begin{array}{l}\text { 3.4.31 Uplink } \\
\text { throughput per } \\
\text { network slice }\end{array}$ & $\begin{array}{l}\text { Guaranteed (and maximum) - Preferred guaranteed data capacity for } \\
\text { the planes transmitting data to ground servers, the whole slice } 1 \mathrm{~Gb} / \mathrm{s} \text {. } \\
5 \mathrm{G} \text { is designed to provide maximum of } 10 \mathrm{~Gb} / \mathrm{s} \text { in uplink, and } 6 \mathrm{G} \text { will } \\
\text { probably outperform it } 10 \text {-fold. }\end{array}$ \\
\hline $\begin{array}{l}3.4 .34 \text { User data } \\
\text { access }\end{array}$ & $\begin{array}{l}\text { No traffic transferred via public Internet: (1) Termination in the } \\
\text { private network, and (2) Local traffic (no internet access). }\end{array}$ \\
\hline $\begin{array}{l}3.4 .35 \mathrm{~V} 2 \mathrm{X} \\
\text { communication }\end{array}$ & $\begin{array}{l}\text { 3: YES - via 5G New Radio (NR) and } 4 \mathrm{G} \text { radio access network } \\
\text { (E-UTRA). }\end{array}$ \\
\hline
\end{tabular}


use cases during and off-flights, there could be even possibilities for the mobile communications ecosystem to consider highly dynamic, nomadic, and adaptive Ad-Hoc aerial networking that can provide communication services supported by aircraft-mounted base stations. 6G could, in fact, serve as complement terrestrial communications with aircraft-mounted base stations and satellite components and provide voice and data services within the limitations of these environments.

\section{Conclusion}

The $6 \mathrm{G}$ visions are still merely under drafting. Nevertheless, there are concrete indications on the forthcoming need for $6 \mathrm{G}$ to tackle the performance requirements of the ecosystem beyond $5 \mathrm{G}$ as various industry initiatives involving key telecom stakeholders show. At the same time, ITU SG13 NET2030 has already identified potential architectural models and use cases that the current $5 \mathrm{G}$ era cannot cope with, justifying thus the $6 \mathrm{G}$ development.

As has been already a "tradition" with previous mobile generations, the $6 \mathrm{G}$ seems to be commercially viable again after a decade from the first deployments of 5G, as of 2030. An important component to create the $6 \mathrm{G}$ requirements and respective systems capable of complying with them, the industry will gather and report experiences from the practical $5 \mathrm{G}$ deployments throughout 2020s.

There are still rather novel enablers that will evolve further and will serve as feasible platform for $6 \mathrm{G}$, one of the most concrete examples being the Network Slicing concept. Nevertheless, the most fruitful development of $6 \mathrm{G}$ will benefit from the deep understanding of realistic vertical requirements and use cases. The adequate assessment of these aspects will be one of the key tasks of the ecosystem in order for standardization bodies to design respective solutions, and for providers of services, devices and technologies to concretize the practical outcomes. Thus, the industry benefits from the related up-to-date methods for the sharing, gathering, and evaluation of requirements as a basis for the development.

\section{Disclaimer}

Please note that the contribution of Dr. Penttinen hereby represents his own views in his personal capacity, and they do not necessarily reflect the position of his current or former employers. 


\section{References}

[1] GSMAi, "Mobile Economy Report 2021," GSMA, July 2021. [Online]. Available: https://www.gsma.com/mobileeconomy/wp-content/upload s/2021/07/GSMA_MobileEconomy2021_3.pdf. [Accessed 14 October 2021].

[2] ITU, "ITU completes evaluation for global affirmation of IMT-2020 technologies," 26 November 2020. [Online]. Available: https://www. itu.int/en/mediacentre/Pages/pr26-2020-evaluation-global-affirmation -imt-2020-5g.aspx. [Accessed 14 October 2021].

[3] ITU, "Focus Group on Technologies for Network 2030," [Online]. Available: https://www.itu.int/en/ITU-T/focusgroups/net2030/Pag es/default.aspx. [Accessed 14 October 2021].

[4] ITU, "Beyond 5G: What's next for IMT?," 2 February 2021. [Online]. Available: https://www.itu.int/en/myitu/News/2021/02/02/09/20/Beyon d-5G-IMT-2020-update-new-Recommendation. [Accessed 14 October 2021].

[5] EU, "Hexa-X vision on 6G and research challenges," Horizon 2020, [Online]. Available: https://hexa-x.eu/. [Accessed 14 October 2021].

[6] Next G Alliance, "Next G Alliance FAQ," ATIS, [Online]. Available: https://nextgalliance.org/about/. [Accessed 14 October 2021].

[7] S. A. A. Jagadeesha R. Bhat, "6G Ecosystem: Current Status and Future," IEEE Access, Vols. 9, 2021, pp. 43134-43167, 26 January 21 2021.

[8] FG-NET2030, "Technical Specification: Network 2030 Architecture Framework," ITU-T, 2020.

[9] Y.-C. L. Shanzhi Chen, "Vision, Requirements, and Technology Trend of 6G: How to Tackle the Challenges of System Coverage, Capacity, User Data-Rate and Movement Speed," IEEE Wireless Communications, pp. 1-11, February 2020.

[10] ITU-T, "Network 2030: A Blueprint of Technology, Applications and Market Drivers Towards the Year 2030 and Beyond," ITU T NET-2030, 2020.

[11] GSMA, "GSMA NG.130 Network Slicing: North America's Perspective," 17 September 2021. [Online]. Available: https://www.gsma.com /newsroom/resources/ng-130-network-slicing-north-americas-perspect ive/. [Accessed 13 October 2021]. 


\section{Biography}

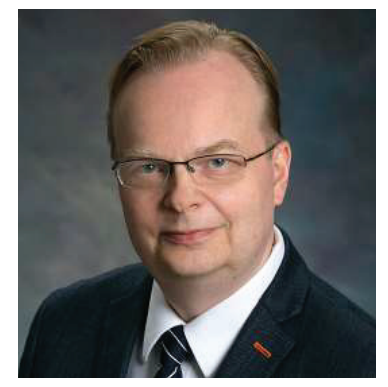

Jyrki T. J. Penttinen received the master's degree in electrical and electronics engineering, and the licentiate and doctor of science in technology degrees from Aalto University (formerly known as Helsinki University of Technology) in 1994, 1999, and 2011, respectively. Dr. Penttinen has worked in research and operational activities with operators, device manufacturers, and trade association in Finland, Spain, Mexico, and the USA. He acts currently as Technical Manager and Instructor in Atlanta, GA, USA, and is author of several $5 \mathrm{G}$ and other telecommunications books. His current interest areas include mobile security, network slicing, vertical applications, and 5G and $6 \mathrm{G}$ evolution. Among other initiatives, he follows up ITU SG13 Future Networks 6G work items. 
